\title{
Evaluation of prescription pattern and patients' opinion on healthcare practices in selected primary healthcare facilities in Ibadan, South-Western Nigeria
}

\author{
Rasaq Adisa, Titilayo O. Fakeye, Victoria O. Aindero
}

Department of Clinical Pharmacy \& Pharmacy Administration, Faculty of Pharmacy, University of Ibadan, Ibadan, Nigeria.

\begin{abstract}
Background: Inappropriate prescribing negatively impacts on health and economy of individual and the society. Objectives: To evaluate the prescribing patterns and patients' opinions on healthcare practices in selected primary healthcare centres (PHC) in Ibadan, South-Western Nigeria.

Methods: A prospective cross-sectional study was carried out among patients and healthcare workers in selected PHCs using semi-structured questionnaires. Also, patients' prescription records were reviewed using the WHO-prescribing indicators.

Results: About one-half $(210 ; 52.5 \%)$ were very satisfied with convenience of obtaining prescribed medicines in the PHCs, accessibility of PHC to abode (158;39.5\%) and affordable medications (136;34.0\%). Patients were dissatisfied with follow-up of care $(191 ; 47.8 \%)$, courtesy of workers $(184 ; 46.3 \%)$ and non-availability of medicines $(138 ; 34.5 \%)$. Number of drugs per encounter was $5.8 \pm 2.3$ and $\%$ encounter with an antibiotic was $>26.8 \%$ in each facility. Hematinics accounted for (814; $35.0 \%$ ), analgesics $(544 ; 23.4 \%)$, antimicrobials $(303 ; 13.0 \%)$ and antihypertensives $(5 ; 0.2 \%)$.

Conclusion: Primary healthcare attendees were satisfied with medication costs affordability and accessibility of PHC to abode but expressed dissatisfaction with follow-up of care and courtesy of workers. Also, inappropriate prescriptions characterized by polypharmacy and overuse of antibiotics were common underscoring the need for regular training of PHC workers on rational drug use and instituting appropriate measures for improvement.

Keywords: Primary healthcare, healthcare workers, prescribing patterns

DOI: http://dx.doi.org/10.4314/ahs.v15i4.35

Cite as: Adisa R, Fakeye TO, Aindero VO. Evaluation of prescription pattern and patients' opinion on bealthcare practices in selected primary healthcare facilities in Ibadan, south-western Nigeria. Afri Health Sci. 2015;15(4):1318-29. bttp:/ / dx.doi.org/10.4314/ abs.v15i4.35
\end{abstract}

\section{Introduction}

Primary healthcare constitutes an integral part of the country's healthcare system and is the level of care responsible for providing basic healthcare services to the generality of the citizens, particularly in the rural areas ${ }^{1}$. In Nigeria, healthcare workers at the primary healthcare (PHC) settings comprise mostly nurses, Community Health Extension Workers (CHEW), Community Health Officers (CHO), health assistant, and pharmacy technicians whose training and primary responsibility

\footnotetext{
Corresponding author:

Rasaq Adisa,

Department of Clinical Pharmacy

\& Pharmacy Administration,

Faculty of Pharmacy,

University of Ibadan, Nigeria.

Telephone no: +2348034226199 .

E-mail: adisaras73@yahoo.co.uk; rasaq.adisa@mail.ui.edu.ng
}

involve prescribing and dispensing of drugs for minor ailments.

The World Health Organization (WHO) defined rational use of drug as patients receiving medications appropriate to their clinical needs in doses that meet their own individual requirements, for an adequate period of time and at the lowest cost to them and their community ${ }^{2,3}$. Thus, appropriate drug utilization is essential in achieving quality of health and medical care for patients.

Drug use is a complex subject involving the prescriber, the patient and the dispenser ${ }^{4}$. Despite the complexity of drug use, a number of indicators have been developed, standardized and evaluated by the $\mathrm{WHO}^{5,6}$. These indicators are used to measure drug use in out-patient facilities and provide measures of the optimal use of resources in the facilities as well as help in correcting deviations from the expected standards and in planning ${ }^{5,6,7}$. Drug use indicators are grouped into three categories namely prescribing indicators comprising average/mean number of drugs per patient encounter; 
percentage of drugs encounter with an injection prescribed; percentage of drugs encounter with an antibiotic prescribed; percentage of drugs prescribed in generic name, and percentage of drugs prescribed from the essential drug list (EDL). Others are patient care and health facility indicators ${ }^{5,6-8}$.

Inappropriate prescribing is known all over the world as a major problem of healthcare delivery especially in developing countries ${ }^{9,10,11,12}$. Irrational prescribing is reported to negatively impact on health and economy of individuals and the society ${ }^{13}$ leading to wastage of resources and widespread health hazards ${ }^{14,15}$. Studies within and outside Nigeria have shown varying degrees of inappropriate prescriptions mostly characterized by polypharmacy, overuse of antibiotics and injections in public sector health facilities ${ }^{11,16-21}$. This practice undermines the provision of high-quality health care to the people especially at the grassroot where majority of the healthcare workers could be classified as semi-skilled in terms of health literacy. Thus, periodic assessment of prescribing patterns and patients' opinion on the treatment practices of healthcare workers at the PHC will help in identifying specific drug-use problems and provide policy makers with relevant information that could be useful in review and implementation of rational drug prescribing. This study therefore used the WHO drug-use indicators to assess the prescribing patterns in selected PHC facilities in Ibadan metropolis, while patients' opinion on healthcare practices was also sought.

\section{Methods}

\section{Study sites}

This study was carried out in eight primary healthcare centres (PHC) from four randomly selected local government areas (LGAs) among the eleven LGAs within Ibadan metropolis. In each LGA, the PHC at the Local Government headquarters and another PHC which was purposively selected for high patronage were considered. Ibadan is the capital city of Oyo State in South-Western Nigeria with an estimated population of $2,550,593$ according to the 2006 population census ${ }^{22,23}$. Ethical approval for the study was obtained from the joint University of Ibadan/University College Hospital Institution Review Board (Approval Number: UI/ EC/13/0155; NHREC/05/01/2008a).

\section{Study design}

A prospective cross-sectional study was conducted among patients and healthcare workers in selected pri- mary healthcare centres from $4^{\text {th }}$ June to $27^{\text {th }}$ August 2013, using pre-tested semi-structured questionnaires. A review of patients' prescription records was also carried out using the World Health Organization (WHO) drug-use evaluation criteria ${ }^{5,6}$.

\section{Inclusion/exclusion criteria and sampling proce- dure}

In the selected PHCs, total sampling of consented patients aged 15 years and above who were concurrently attending the facilities for treatment was done, after they had been attended to by the primary care provider. Also, all the consented healthcare workers in attendance at their respective practice sites were enrolled. Objectives of the study were explained to patients and healthcare workers individually, after which an informed verbal consent was obtained from individuals to signify their intention to participate in the study. Participation and consent of pupil participants between the age of $\geq 15$ and $<18$ years was endorsed by the teacher who accompanied them to the facility, since individuals within these age groups were generally considered as "minor". Clarifications were made for patients who did not understand English Language by the principal investigator. Translation and back-translation of responses were subsequently done to ensure response consistency. Pregnant women, as well as non-consented patients and healthcare workers were excluded from the study. Participation was voluntary and respondents were assured of anonymity and confidentiality of their responses. Subsequently, prescription records in the facilities were concurrently reviewed and evaluated.

\section{Sample size determination}

The target sample size was calculated based on the estimated population of 5280 patients from the eight PHC facilities for a study period of 12 consecutive weeks. Preliminary information from the medical record unit of the PHCs indicated that a facility usually has an average of 55 patients per week (i.e. $55 \times 12$ weeks $\times 8$ PHCs $=5280)$. Also, in each PHC, an average of 13 healthcare workers of different cadres were on the employment pay-roll, giving an estimated population of $104 \mathrm{HCW}$ for the eight facilities surveyed. With the estimated population and assumptions of 5\% margin of error and 95\% confidence level, a target sample size of approximately 400 prescriptions, 400 patients and 91 healthcare workers was computed using a sample size calculator (www.surveysystem.com/sscal.html) ${ }^{24}$, with the inclusion of a $10 \%$ attrition rate. 


\section{Pre-test and validation of instruments}

The questionnaires and drug-use data collection form were assessed for clarity and content validity by two academic scholars. The questionnaires were pretested among five healthcare workers and ten patients in one of the excluded PHCs. Based on validity assessment and pre-test, some modifications were made, especially questions with dichotomous Yes/No response options which were rephrased in ordinal scales to remove ambiguity and ensuring clarity of respondents' opinion.

\section{Data collection}

Patients' interview was guided by the questionnaire consisting of two sections. Section A clarified socio-demographic characteristics, while section B obtained information on patients' opinion on the treatment practices of healthcare workers including mode of approach to care and treatment, follow-up system on care in the PHC, offer to counsel by the HCW, courtesy of healthcare worker to patients, and accessibility of PHC to patient's residence among others. The self-administered questionnaire by the HCW comprised two sections. Section A obtained socio-demographic data including length/year of practice in respective PHC, and section B obtained information on source(s) of medicines routinely dispensed or recommended for patients, and the most frequently dispensed medicines in the PHC among other questions. The questionnaire-guided patients' interview took about 20 minutes to complete, while the self-administered questionnaire by HCW took about 10 minutes.

\section{Data analysis}

Data was sorted, coded and analyzed using Predictive Analytics Software version 20. Descriptive statistics including frequency, mean \pm standard deviation and percentage were used to summarize the data. Ranked variables were summarized using median value or fiftieth percentile while associations among patients of different educational background and opinions on the healthcare practices were evaluated using Kruskal-Wallis test. The information from the prescription sheets were pooled into Microsoft Excel and analysed using the WHO core prescribing indicators ${ }^{5,6}$. Binary categorization of drug-use indicator performance for the facilities was developed utilizing a cut-off derived from the standard reference values for drug-use indicators in public sector health facility ${ }^{16}$. In this study, value less than the upper limit of standard value was considered as "good performance" while value greater than the upper limit was considered as "poor performance" with respect to the $\%$ of drugs encounter with an antibiotic and injection prescribed. Also, for the percent of drugs prescribed by generic name and from the EDL, value equal to $100 \%$ was considered as "good performance" and value less than $100 \%$ as "poor performance". Associations/differences between the PHCs regarding druguse indicator performance were tested using one-way analysis of variance, Chi-square or Fischer exact test as appropriate at $\mathrm{p}<0.05$ considered significant.

\section{Results}

A total of 400 copies of questionnaires distributed to patients within the study period were retrieved and analysed, giving a response rate of $100 \%$. Two hundred and eighty-three $(70.8 \%)$ patients were aged $21-30$ years, 385 $(96.3 \%)$ were female and $15(3.8 \%)$ were male. Majority $(311 ; 77.6 \%)$ were traders and had secondary education (262; 65.5\%) (see Table 1).

Patients'opinions on the treatment practices of HCW showed that about one-half $(210 ; 52.5 \%)$ were very satisfied with ease/convenience of obtaining prescribed medicines in the facilities, accessibility of primary healthcare centre (PHC) to abode $(158 ; 39.5 \%)$, and affordable medications $(136 ; 34.0 \%)$. 
Table 1: Socio-demographic data of patients $(n=400)$

\begin{tabular}{lll}
\hline Characteristics & Frequency & Percent frequency \\
\hline Age (years) & 11 & 2.8 \\
$15-20$ & 283 & 70.8 \\
$21-30$ & 56 & 14.0 \\
$31-40$ & 30 & 7.5 \\
$41-50$ & 16 & 4.0 \\
$51-60$ & 4 & 1.0 \\
Above 60 & & \\
Sex & 15 & 3.8 \\
Male & 385 & 96.3 \\
Female & & \\
Educational & & \\
qualification & 23 & 5.8 \\
No formal education & 80 & 20.0 \\
Primary & 262 & 65.5 \\
Secondary & 35 & 8.8 \\
Tertiary or post & & \\
secondary & & \\
Marital status & 48 & 12.0 \\
Single & 351 & 87.8 \\
Married & 1 & 0.3 \\
Divorced & 0 & 0 \\
Widowed & & \\
Occupation & 311 & 77.6 \\
Trading/business & 38 & 9.5 \\
Public/civil servant & 25 & 6.3 \\
Artisans & 20 & 5.0 \\
Student & 6 & 1.5 \\
Farming & & \\
Duration of attending \\
the PHC (in years) & & 6.3 \\
$<1$ & 25 & 74.8 \\
1-5 & 299 & 16.0 \\
6-10 & 64 & 3.0 \\
11-15 & 12 & \\
\hline
\end{tabular}

Patients expressed dissatisfaction with follow-up of care $(191 ; 47.8 \%)$, courtesy of workers $(184 ; 46.3 \%)$ and non-availability of prescribed medicines (138; $34.5 \%$ ) (see Table 2). Patients with secondary and tertiary education were mostly dissatisfied with courtesy of workers as indicated by the lower mean ranks (MR) of 192.6 and 145.1 respectively, compared to attendee with no formal education having MR of 269.4 and primary education with MR of 222.0. $(\mathrm{p}=0.00)$. Details of patients' opinion on healthcare practices in the facilities are shown in Table 2.

Ninety-one copies of questionnaires distributed among healthcare workers were retrieved and analysed, giving a response rate of $100 \%$. The cadres of healthcare workers in the PHC facilities surveyed included community health extension workers $(59 ; 64.8 \%)$, nurses (20; $22.0 \%)$, community health officers $(9 ; 9.9 \%)$, pharmacy technicians $(2 ; 2.2 \%)$, and physician $(1 ; 1.1 \%)$. 
Table 2: Patients' opinion on healthcare workers' treatment practices in the facilities $(n=400)$

\begin{tabular}{|c|c|c|c|c|c|c|c|}
\hline \multicolumn{8}{|c|}{ Response, N (\%) } \\
\hline Variable & $\begin{array}{l}\text { Extremely } \\
\text { satisfied }\end{array}$ & $\begin{array}{l}\text { Very } \\
\text { satisfied }\end{array}$ & Satisfied & Dissatisfied & $\begin{array}{l}\text { Extremely } \\
\text { dissatisfied }\end{array}$ & $\begin{array}{l}\text { Median (50 } \\
\text { percentile) }\end{array}$ & $\begin{array}{l}\text { K-W p-value } \\
\text { for } \\
\text { educational } \\
\text { background }\end{array}$ \\
\hline $\begin{array}{l}\text { 1. Accessibility of } \\
\text { the PHC to } \\
\text { residence }\end{array}$ & $55(13.8)$ & $158(39.5)$ & $124(31.0)$ & $56(14.0)$ & $7(1.80)$ & 4 & 0.07 \\
\hline $\begin{array}{l}\text { 2. Convenience of } \\
\text { obtaining prescribed } \\
\text { medicines in the } \\
\text { PHC }\end{array}$ & $44(11.0)$ & $210(52.5)$ & $146(36.5)$ & 0 & 0 & 4 & $0.02 *$ \\
\hline $\begin{array}{l}\text { 3.Time spent with } \\
\text { the HCW at every } \\
\text { encounter }\end{array}$ & $26(6.5)$ & $165(41.3)$ & $209(52.3)$ & 0 & 0 & 3 & 0.15 \\
\hline $\begin{array}{l}\text { 4. Mode of approach } \\
\text { to treatment and } \\
\text { care by HCW }\end{array}$ & $23(5.8)$ & $186(46.5)$ & $189(47.3)$ & $2(0.5)$ & 0 & 4 & 0.29 \\
\hline $\begin{array}{l}\text { 5. Affordability of } \\
\text { costs of prescribed } \\
\text { medicines per } \\
\text { encounter }\end{array}$ & $80(20.0)$ & $136(34.0)$ & $91(22.8)$ & $93(23.3)$ & 0 & 4 & $0.02 *$ \\
\hline $\begin{array}{l}\text { 6. Availability of } \\
\text { prescribed medicines } \\
\text { in the dispensary }\end{array}$ & $30(7.5)$ & $113(28.3)$ & $113(28.3)$ & $138(34.5)$ & $6(1.5)$ & 3 & 0.93 \\
\hline $\begin{array}{l}\text { 7. Follow up system } \\
\text { on care by the HCW }\end{array}$ & $3(0.8)$ & $39(9.8)$ & $88(22.0)$ & $191(47.8)$ & $79(19.8)$ & 2 & $0.004 *$ \\
\hline $\begin{array}{l}\text { 8. Offer to counsel } \\
\text { by the HCW }\end{array}$ & $51(12.8)$ & $218(54.5)$ & $130(32.5)$ & $1(0.3)$ & 0 & 4 & 0.24 \\
\hline $\begin{array}{l}\text { 9. Adequacy of } \\
\text { information on } \\
\text { medication use }\end{array}$ & $28(7.0)$ & $224(56.0)$ & $143(35.8)$ & $5(1.3)$ & 0 & 4 & 0.80 \\
\hline $\begin{array}{l}\text { 10. Courtesy of } \\
\text { HCW to patients } \\
\text { while in the PHC }\end{array}$ & $8(2.0)$ & $55(13.9)$ & $84(21.2)$ & $184(46.3)$ & $66(16.5)$ & 2 & $0.00 *$ \\
\hline $\begin{array}{l}\text { 11. Privacy or } \\
\text { confidentiality of } \\
\text { records/information } \\
\text { by the HCW }\end{array}$ & $60(15.0)$ & $189(47.3)$ & $150(37.5)$ & $1(0.3)$ & 0 & 4 & $0.02 *$ \\
\hline
\end{tabular}

Extremely satisfied $=5$, Very satisfied $=4$, Satisfied $=3$, Dissatisfied $=2$, Extremely dissatisfied $=1, \mathrm{HCW}=$ Healthcare worker, PHC $=$ Primary healthcare centre, Level of statistical significance $\mathrm{p}<0.05$, *Significant difference with Kruskal-Wallis $(\mathrm{K}-\mathrm{W})$ test for the distribution of rank variables among respondents with different educational background

Year of practice of HCW in respective PHC showed that four (4.4\%) had less than one year, $35(38.5 \%)$ had been practiced in the PHC for 1-5 years, $27(29.7 \%)$ for 6-10 years, $10(11.0 \%)$ for $11-15$ years, $11(12.1 \%)$ for 16-20 years, $2(2.2 \%)$ for $21-25$ years, and $2(2.2 \%)$ had been in the PHC for 26 years and above. The source of medicines recommended in the facilities included, in different combinations, central medical store $(67$; $35.4 \%)$, drug revolving funds system $(25 ; 13.2 \%)$, bulk purchase from the wholesaler and re-sell/retail to pa- tients at a reasonable cost $(21 ; 11.1 \%)$, while $76(40.2 \%)$ reported that they usually recommend for patients to buy their medicines elsewhere.

The WHO drug-use indicators for prescribed medicines in the facilities showed that the mean number of drugs prescribed per encounter was $5.8 \pm 2.3$ (range: 1 to 14$)$, percentage of drugs prescribed by generic name was $<100 \%$ for each facility, $\%$ of drugs encounter with an antibiotic was $>26.8 \%$ (standard value: $20-26.8 \%$ ) 16 for each facility (see Table 3). There were statistically 
significant differences in the drug-use indicator performance of the facilities with respect to mean number of drugs per encounter $(\mathrm{F}=27.2, \mathrm{p}=0.00), \%$ of drugs en- counter with an antibiotic $(\mathrm{p}=0.034)$, and $\%$ of drugs prescribed by generic name $(p=0.00)$. Details of druguse indicator performance for each facility are shown in Table 3.

Table 3: Comparison of drug-use indicator performance for the facilities

\begin{tabular}{|c|c|c|c|c|c|c|c|}
\hline LGA & PHC & $\begin{array}{l}\text { Number of } \\
\text { prescription } \\
\text { encounter } \\
\text { per facility }\end{array}$ & $\begin{array}{l}\begin{array}{l}\text { Mean number of } \\
\text { drugs per } \\
\text { encounter }\end{array} \\
(\mathrm{LRV}=1.6-1.8) \\
\mathrm{N} \text {; Mean } \pm \text { SD }\end{array}$ & $\begin{array}{l}\text { \% of drug } \\
\text { encounter with } \\
\text { an antibiotic } \\
(\mathrm{LRV}=\mathbf{2 0 - 2 6 . 8 )} \\
\text { n (\%) }\end{array}$ & $\begin{array}{l}\text { \% of drug } \\
\text { encounter with } \\
\text { an injection } \\
(\mathrm{LRV}=13.4 \text { - } \\
24.1) \\
\text { n (\%) }\end{array}$ & $\begin{array}{l}\text { \% of total } \\
\text { drugs } \\
\text { prescribed in } \\
\text { generic } \\
(\mathrm{LRV}=100)\end{array}$ & $\begin{array}{l}\% \text { of total } \\
\text { drugs } \\
\text { prescribed } \\
\text { from EDL } \\
(L R V=100)\end{array}$ \\
\hline \multirow[t]{2}{*}{ IBN } & $\mathrm{IOHC}$ & 50 & $200 ; 4.0 \pm 1.2$ & $24(48.0)$ & $2(4.0)$ & 59.5 & 98.2 \\
\hline & $\mathrm{BHC}$ & 50 & $279 ; 5.6 \pm 1.9$ & $35(70.0)$ & $22(44.0)$ & 63.3 & 99.3 \\
\hline \multirow[t]{2}{*}{ IBNE } & IRHC & 50 & $408 ; 8.2 \pm 2.6$ & $38(76.0)$ & $42(84.0)$ & 75.4 & 99.8 \\
\hline & OAHC & 50 & $250 ; 5.0 \pm 1.8$ & $23(46.0)$ & $46(92.0)$ & 82.0 & 99.6 \\
\hline \multirow[t]{2}{*}{ AKYL } & $\mathrm{MHC}$ & 50 & $328 ; 6.6 \pm 2.1$ & $27(54.0)$ & $39(78.0)$ & 68.9 & 99.4 \\
\hline & $\mathrm{OHC}$ & 50 & $362 ; 7.2 \pm 1.6$ & $14(28.0)$ & $45(90.0)$ & 67.1 & 99.5 \\
\hline \multirow[t]{5}{*}{ EGBD } & $\mathrm{AHC}$ & 50 & $272 ; 5.4 \pm 2.2$ & $32(64.0)$ & $11(22.0)$ & 59.8 & 97.9 \\
\hline & WHC & 50 & $\begin{array}{l}226 ; 4.6 \pm 1.6 \\
F=27.2 ; p=0.00\end{array}$ & $27(54.0)$ & $3(6.0)$ & 68.2 & 99.0 \\
\hline & & & \multicolumn{2}{|c|}{$\begin{array}{l}\text { Facility performance for } \% \\
\text { encounter with an antibiotic }\end{array}$} & \multicolumn{3}{|c|}{$\begin{array}{l}\text { Facility performance for } \% \text { of drug prescribed } \\
\text { in generic }\end{array}$} \\
\hline & & & $\begin{array}{l}\text { Good } \\
\text { (Value }<27 \% \text { ) }\end{array}$ & $\begin{array}{l}\text { Poor } \\
\text { (Value }>\mathbf{2 7 \%} \text { ) }\end{array}$ & $\begin{array}{l}\text { Good } \\
(\text { Value }=100 \%)\end{array}$ & $\begin{array}{l}\text { Poor } \\
\text { (Value } \\
<100 \%\end{array}$ & \\
\hline & & & n (\%) & n (\%) & n $(\%)$ & n (\%) & \\
\hline \multirow[t]{2}{*}{ IBN } & $\mathrm{IOHC}$ & IBADAN- & $17(70.8)$ & $7(29.2)$ & $44(88.0)$ & $6(12.0)$ & \\
\hline & $\mathrm{BHC}$ & URBAN & $29(82.9)$ & $6(17.1)$ & $20(40.0)$ & $30(60.0)$ & \\
\hline \multirow[t]{2}{*}{ IBNE } & IRHC & & $34(89.5)$ & $4(10.5)$ & $14(28.0)$ & $36(72.0)$ & \\
\hline & ОАНС & & $18(78.3)$ & $5(21.7)$ & $34(68.0)$ & $16(32.0)$ & \\
\hline \multirow[t]{2}{*}{ AKYL } & MHC & IBADAN- & $24(88.9)$ & $3(11.1)$ & $26(52.0)$ & $24(48.0)$ & \\
\hline & $\mathrm{OHC}$ & SEMI & $13(92.9)$ & $1(7.1)$ & $29(58.0)$ & $21(42.0)$ & \\
\hline \multirow[t]{3}{*}{ EGBD } & $\mathrm{AHC}$ & URBAN & $22(68.8)$ & $10(31.3)$ & $24(48.0)$ & $26(52.0)$ & \\
\hline & WHC & & $16(59.3)$ & $11(40.7)$ & $16(32.0)$ & $34(68.0)$ & \\
\hline & & & \multicolumn{2}{|l|}{$\mathrm{p}=0.03$} & $\mathrm{p}=0.00$ & & \\
\hline
\end{tabular}

LGA $=$ Local Government Area, IBN = Ibadan North, IBNE $=$ Ibadan North East, AKYL $=$ Akinyele, EGBD $=$ Egbeda, Ibadan urban comprised IBN \&IBNE, Ibadan semi-urban comprised AKYL \& EGBD; PHC = Primary Healthcare Centre, IOHC = Idi-Ogungun Health Centre, BHC $=$ Bashorun Health Centre, IRHC = Iwo Road Health Centre, $\mathrm{OAHC}=$ Oke-Adu Health Centre, $\mathrm{MHC}=$ Moniya Health Centre, $\mathrm{OHC}=$ Ojoo Health centre, $\mathrm{AHC}$ $=$ Alakia Health Centre, $\mathrm{WHC}=$ Wakajaye Health Centre,, $\mathrm{EDL}=$ Essential Drug List, $\mathrm{LRV}=$ Local reference value, $\mathrm{N}=$ Total number of drugs prescribed, $\mathrm{n}=$ number of encounter, $\mathrm{SD}=$ Standard deviation

Out of a total of 2325 medicines prescribed, hematinics/vitamin supplements constituted the highest pro- portions $(814 ; 35.0 \%)$. The details of prescribed medicines in the facilities are shown in Tables 4, 5 and 6. 
Table 4: Profile of prescribed analgesics, hematinics and antihistamine in the facilities

\begin{tabular}{lll}
\hline Drug category/class & Specific drug type & Number (\%) \\
\hline Vitamins/hematinics/mineral supplement $(\mathbf{n}=\mathbf{8 1 4})$ & Vitamin B complex & $336(41.3)$ \\
& Folic acid & $176(21.6)$ \\
& Ascorbic acid (Vitamin C) & $171(21.0)$ \\
& Iron/vitamin B12/folic acid & $48(5.9)$ \\
& combination & $36(4.4)$ \\
& Multivitamins & $28(3.4)$ \\
& Ferrous sulphate & $14(1.7)$ \\
Analgesics/antipyretics/anti-inflammatory $(\mathbf{n}=\mathbf{5 4 4 )}$ & Calcium & $5(0.6)$ \\
& Zinc sulphate & $440(80.9)$ \\
& Paracetamol & $90(16.5)$ \\
& Diclofenac & $6(1.1)$ \\
& Ibuprofen & \\
\cline { 2 - 3 }
\end{tabular}

Antihistamine/antiallergic $(\mathbf{n}=99)$

$\begin{array}{lc}\text { Acetylsalicylic acid } & 4(0.7) \\ \text { Methylsalicylate } & 2(0.4) \\ \text { Piroxicam } & 1(0.2) \\ \text { Trypsin/Chymotrypsin } & 1(0.2) \\ \text { Chlorpheniramine maleate } & 65(65.6) \\ \text { Promethazine } & 20(20.2) \\ \text { Meclozine } & 4(4.0) \\ \text { Hydrocortisone } & 4(4.0) \\ \text { Prednisolone } & 3(3.0) \\ \text { Cetrizine } & 2(2.0)\end{array}$

Table 5: Profile of prescribed antimalarial and antibiotics in the facilities

\begin{tabular}{|c|c|c|}
\hline Drug category/class & Specific drug type & Number (\%) \\
\hline \multirow{19}{*}{ Antimicrobials $(n=303)$} & Amoxicillin & $77(25.4)$ \\
\hline & Metronidazole & $61(20.1)$ \\
\hline & Gentamicin & $32(10.6)$ \\
\hline & Erythromycin & $26(8.6)$ \\
\hline & Ciprofloxacin & $20(6.6)$ \\
\hline & Ampicillin/cloxacillin & $18(5.9)$ \\
\hline & Co-trimoxazole & $13(4.3)$ \\
\hline & Ampicillin & $9(3.0)$ \\
\hline & Cefuroxime & $7(2.3)$ \\
\hline & Cephalexin & $7(2.3)$ \\
\hline & Ofloxacin & $7(2.3)$ \\
\hline & Procaine penicillin & $7(2.3)$ \\
\hline & Crystalline penicillin & $5(1.7)$ \\
\hline & Amoxicillin/clavulanic acid & $4(1.3)$ \\
\hline & Phythalysulfathiazole & $3(1.0)$ \\
\hline & Doxycycline & $2(0.7)$ \\
\hline & Sulfadimidine & $2(0.7)$ \\
\hline & Tetracycline & $2(0.7)$ \\
\hline & Cefixime & $1(0.3)$ \\
\hline \multirow[t]{5}{*}{ Antimalarial $(n=299)$} & Artemeter/lumefantrine & $224(74.9)$ \\
\hline & Artesunate/amodiaquine & $56(18.7)$ \\
\hline & Artesunate monotherapy & $12(4.0)$ \\
\hline & Quinine & $6(2.0)$ \\
\hline & Sulphadoxine/pyrimethamine & $1(0.3)$ \\
\hline
\end{tabular}


Table 6: Summary of other prescribed medicines in the facilities

\begin{tabular}{|l|l|l|}
\hline Drug category/class & Specific drug type & Number (\%) \\
\hline Antacids (n=35) & Magnesium trisilicate & $23(65.7)$ \\
\hline & $\begin{array}{l}\text { Simethicone/aluminiumhydroxide/magnesium } \\
\text { combination }\end{array}$ & $8(22.9)$ \\
\hline & $\begin{array}{l}\text { Aluminium hydroxide and magnesium } \\
\text { hydroxide combination }\end{array}$ & $3(8.6)$ \\
\hline & Aluminium hydroxide & $1(2.9)$ \\
\hline Antihelmintics (n=31) & Pyrantel permoate & $21(67.7)$ \\
\hline & Mebendazole & $7(22.6)$ \\
\hline & Levamizole & $3(9.7)$ \\
\hline Anxiolytics (n=24) & Diazepam & $21(87.5)$ \\
\hline Antihypertensive (n=5) & Bromazepam & $3(12.5)$ \\
\hline & Nifedipine & $1(20.0)$ \\
\hline & Atenolol & $1(20.0)$ \\
\hline & Methyldopa & $1(20.0)$ \\
\hline & Amiloride/hydrochlorthiazide & $1(20.0)$ \\
\hline Antifungals (n=4) & Amlodipine & $1(20.0)$ \\
\hline & Clotrimazole & $2(50.0)$ \\
\hline & Nystatin & $1(25.0)$ \\
\hline *Others & Ketoconazole & $1(25.0)$ \\
\hline & & $167(7.2)$ \\
\hline
\end{tabular}

*Include Oral Rehydration Salt (ORS) ( $\mathrm{n}=79)$, Metoclopramide $(\mathrm{n}=43)$, Hyoscine-N-butyl bromide $(\mathrm{n}=19)$, Glucose $(\mathrm{n}=8)$, Calamine lotion $(\mathrm{n}=6)$, Tetanus toxoid $(\mathrm{n}=4)$, Mist potassium citrate $(\mathrm{n}=2)$, Bisacodyl $(\mathrm{n}=1)$, Dequalinium hydrochloride $(\mathrm{n}=1)$, Glycerin of borax $(n=1)$, Iodine $(n=1)$, Salbutamol $(n=1)$.

\section{Discussion}

In this study, a substantial number of PHC attendees were women, mostly with secondary education and in their younger ages of 21-30 years. This seems consistent with the report in literature that women in Nigeria constitute $60-79 \%$ of the rural workforce ${ }^{25}$, which is a statutory location where the primary healthcare centres are generally situated. Also, evidence from around the world including Nigeria has shown that women lag behind in education and employment, and tend to have lower levels of literacy compared to men ${ }^{25,26}$. In addition, studies across different settings have found that, on average, women reported more symptoms than men even when their illness status was similar ${ }^{27}$, and that men tend to seek healthcare at later stages and at a higher level of healthcare as compared to women ${ }^{28}$. Therefore, high patronage of the PHCs by younger women may further emphasize the need to strengthen and consolidate the primary healthcare services, since studies have shown that women in low income countries including Nigeria tend to have reproductive health challenges which places a high financial and medical burden on women than men ${ }^{25,29-32}$. This is in addition to the fact that women's empowerment which is the third of the eight millennium development goals underpin the achievement of all the other Millennium Development Goals ${ }^{25,29,30}$.

It is noteworthy that a high proportion of the patients expressed satisfaction with ease or convenience of obtaining the prescribed medicines in the PHC and accessibility of healthcare facility to their abode. This finding possibly implies that the local government authority saddled with the primary responsibility of constructing primary healthcare centre at their respective domain need to be commended. However, it was observed that a sizeable number of patients were dissatisfied with non-availability of prescribed medicines in the PHC facilities, thereby prompting the need to recommend purchase of medicine elsewhere. This practice usually creates avenue for treatment of non-adherence among patients generally. The availability and convenience of obtaining prescribed medicines in a facility are critical components that may largely determine the pub- 
lic health facility's performance in terms of medicine accessibility by patients. Literature reports that about one-third of the world population lacks access to essential medicines leading to morbidity and mortality particularly for infectious and chronic illness ${ }^{4,7}$. Equipping the primary healthcare centres with adequate essential medicines and qualified healthcare personnel should therefore be given priority attention. The 1978 Alma Ata conference identified the availability, quality and rational use of essential medicines as one of the cardinal components of primary healthcare ${ }^{33,34}$.

In this study, a substantial number of patients were satisfied with affordable medications but expressed dissatisfaction with follow-up system on care and courtesy of HCW while in the PHC. Patients' expression of dissatisfaction with the follow-up system on care is a call for concern, though, the non-follow-up of care by PHC workers may be expected since PHCs are statutorily established to cater for minor ailments which may not necessarily require active follow-up on care. Any situation of complicated or chronic medical condition at the PHC level are to be promptly and properly referred to the nearest secondary or tertiary healthcare settings. However, these findings further underscore the need for periodic evaluation of patients' opinion on the healthcare practices at the public health facilities, so as to ensure identification of problem areas to focus on for future intervention. Patients' expression of dissatisfaction with courtesy of PHC workers is an issue of great concern that needs to be addressed by all PHC stakeholders. Courtesy and use of empathy during patient-provider interaction should be advocated and encouraged, so as to ensure truthful and mutual therapeutic relationship between the provider and patients ${ }^{35-37}$.

Majority reported satisfaction with the mode of approach to treatment and care by the HCW, while substantial proportions were barely satisfied with the time spent during treatment in the PHC. It is however important to note that the quality and content of information provided during counselling are key determinants of patients' satisfaction with the counselling, while prompt and active attention to patient's need and complaints may be a key element in gauging the effectiveness of service delivery of a facility. Primary healthcare workers may need to take cognizance of these findings and consider appropriate measures for improvement.
In this study, the healthcare workers involved in prescribing and dispensing of medicines were largely community health workers and nurses. Babalola et $\mathrm{al}^{21}$ also reported these cadres of healthcare workers as the predominant healthcare professionals in the primary healthcare system. The dearth of skilled and qualified healthcare personnel including physician and pharmacist to serve in rural and remote areas where most of the PHCs were located might have accounted for undue involvement of different cadres of semi-skilled healthcare workers whose training only entails prescribing of medicines for minor ailments. Inadequate knowledge of the primary healthcare workers on the rational chronological order of the dispensing process had earlier been reported in similar settings ${ }^{38}$. However, considering the importance, patronage and proximity of primary healthcare to the generality of citizens, it has become essential to allocate more resources to such settings with an attractive remuneration package so as to continuously encourage and motivate qualified and skilled healthcare workers especially physicians and pharmacists to practice at the PHC facilities, in order to assure the quality of primary healthcare delivery.

It is noteworthy to mention that polypharmacy practice, inappropriate use of antibiotics and injections were common in the facilities surveyed. This is consistent with studies in public sector health facilities within and outside Nigeria $a^{11,21,39-42}$. Inappropriate prescribing is reported to negatively impact on health and economics of individuals and the society leading to wastage of scarce resources and widespread health hazards ${ }^{13,14,15}$.

In this study, prescribing by generic name could be described as moderate compared to the standard value of $100 \%$. The percentage of generic prescription is higher than values reported in other studies conducted in developing countries ${ }^{11,16,18,43-45}$. However, much higher values of generic prescription $(75.0 \%$ to $99.8 \%$ ) have been reported from Bangladesh ${ }^{44}$ and Cambodia ${ }^{46}$. Prescribing in generics without compromising therapeutic efficacy may be better appreciated by the patient on account of cost reduction compared to the branded drug products $^{40}$. In addition to the lower economic cost to patients, generic prescribing will eliminate or reduce the incidence of therapeutic duplication or errors ${ }^{47}$. Furthermore, it was observed that substantial proportions of prescribed medicines were from the EDL with a higher value than what has been reported in most of the previous studies ${ }^{21,44,45,48-50}$. Prescribing from the 
National EDL provides a framework for rational prescribing with lower cost than prescribing newer drugs or medicines not in the EDL ${ }^{51}$.

Hematinics/vitamin supplements were the most commonly prescribed medicines in the facilities. Other studies have alsoreported analgesics and hematinics as the frequently prescibed medicines in the facilities studied ${ }^{11,21,39-42}$. The increased prescription of artemeter-lumefantrine for malaria showed a good compliance to the WHO recommendations and the National Standard Treatment Guidelines (STG) for malaria treatment ${ }^{52}$. However, presumptive use of artemisinin-based drugs for empirical treatment of acute uncomplicated malaria may need to be discouraged as this totally deviates from the WHO and STG for malaria ${ }^{52}$. In addition, the percentage of antibiotics prescribed in this study is higher than reported in most other studies ${ }^{21,40}$. Hogerzeil et al ${ }^{42}$ reported figures of $47.5 \%$ to $100 \%$ of encounters with antibiotic prescriptions, while a lower rate $(17.5 \%)$ of antibiotics prescription was reported in $\mathrm{Nepal}^{43}$. Studies have reported that antibiotics are one of the groups of drugs involved in adverse drug reactions (ADRs) and are greatly misused and overprescribed in Nigeria ${ }^{53,54}$. Inappropriate use of antibiotics should be discouraged as this may potentially lead to antimicrobial resistance and increase the necessity to use more expensive antibiotics to treat common and life-threatening infections ${ }^{40}$. Regular and ongoing training on rational use of drugs is therefore advocated for all categories of healthcare providers involved in prescribing and dispensing of drugs at the PHC so as to continuously ensure optimal care for the people. In this study, it was noted that prescription of medications for chronic condition was generally low, possibly implying that $\mathrm{HCW}$ at the PHC level were within the limit of their statutory job description with regard to the treatment and management of chronic diseases.

Despite the useful information from this study, it was limited by the fact that patient care and health facility indicators which are part of the comprehensive WHO drug-use evaluation criteria ${ }^{5,6,8}$ were not explored. However, this information might have allowed the opportunity of assessing the average consultation and dispensing time as a measure to gauge the effectiveness of service delivery in the PHC, as well as ascertaining patients' knowledge of the correct usage of prescribed regimen. Nonetheless, future studies may need to consider inclusion of more PHC facilities, as well as criti- cally assess other drug-use indicators, so as to ensure far reaching conclusions.

\section{Conclusion}

Patrons of primary healthcare facilities in Ibadan metropolis were mostly satisfied with convenience of obtaining prescribed medicines in the PHC, accessibility of facility to places of abode and affordable medications but were dissatisfied with the follow-up system on care, courtesy of HCW during treatment and non-availability of prescribed medicines in the PHC's dispensary suggesting needs for PHC workers to redouble their efforts in order to continuously ensure improved care. Also, moderate generic prescription as well as inappropriate prescribing characterized by polypharmacy, overuse of antibiotics and injections were observed underscoring the need for regular and ongoing training on rational use of drugs for the PHC workers, while qualified healthcare personnel, especially physicians and pharmacists need to be motivated and encouraged to practice at the PHC level, so as to assure quality healthcare to the people.

\section{Conflict of interest statement}

None to declare by the authors

\section{Funding information}

None to declare by the authors

\section{References}

1. Abdulraheem IS, Oladipo AR, Amodu MO. Primary healthcare services in Nigeria: critical issues and strategies for enhancing the use by the rural communities. Journal of Public Health and Epidemiology 2012;4(1):5-13.

2. World Health Organization (WHO). The rational Use of Drugs. Reports of the conference of Experts. World Health Organization, 1985. Geneva. Retrieved October 25, 2013, from http://www.who.int/medicine/

3. World Health Organization (WHO). Rational use of medicines by prescribers and patients. WHO, 2005. Geneva. Retrieved October 25, 2013, from http://www. who.int/medicine/

4. Angamo MT, Wabe NT, Raju NJ. Assessment of patterns of drug use by using World Health Organization's prescribing, patient care and health facility indicators in selected health facilities in southwest Ethiopia. Journal of Applied Pharmacentical Science 2011; 01(07):62-66

5. World Health Organization (WHO). How to investigate drug use in health facilities. Selected drug use indicators. Action programme on essential drugs. World Health Organization, 1993. Geneva. Pp1-87. 
6. World Health Organization (WHO). Action Programme on Essential Drugs. Model guide to good prescribing. World Health Organization, 1991. Geneva. Retrieved April 20, 2014, from http://www.who.int/

7. Odusanya OO. Drug-use indicators at secondary health care facility in Lagos, Nigeria. J. Commun. Med. Health Care 2004; 6(1):21 PubMed -24.

8. World Health Organization (WHO). Promoting rational use of medicines: core components. WHO policy perspectives on medicines 2002; No 5 document, WHO/EDM/2002.3, Geneva. Retrieved April 20, 2014 from http://www.who.int/medicines/

9. Erah PO, Olumide GO, Okhamafe AO. Prescribing practices in two health care facilities in Warri, southern Nigeria: A comparative study. Trop J Pharm Res 2003; 2(1):175 PubMed -182.

10. Rahana HS, Nagarani MA, Rehan MA. Study on the drug prescribing pattern and use of antimicrobial agents at a tertiary care teaching hospital in Eastern Nepal. Indian J Pharmacol 1998;30: 175-180 PubMed

11. Enato EFO, Sounyo AA, Madadi P. Assessment of disease profiles and drug prescribing patterns of healthcare facilities in Edo state, Nigeria. Journal of Public Health in Africa 2012;3:e25:101-106.

12. Bhatt SP. Rational Use of Medicine. International Journal of Pharmaceutical Research 2010; 2:69

13. Bashrahil KA. Indicators for rational drug use and health services in Hadramout, Yemen. Eastern Mediterr H J 2010;16:151-155.

14. World Health Organization. WHO medicines strategy 2004-2007: countries at the core. WHO/ EDM.2004.2. World Health Organization, 2004. Geneva. Retrieved April 20, 2014 from http://www.who.int/ 15. Ghimire S, Nepal S, Bhandari S, Nepal P, Palaian S. A prospective surveillance of drug prescribing and dispensing in a teaching hospital in western Nepal. J Pak Med Assoc 2009;59:726-731 PubMed .

16. Isah AO, Laing R, Quick J, Mabadeje AFB, Santoso B, Hogerzeil H, Ross-Degnan D. The development of reference value for the WHO health facility core prescribing indicators. West Afr J Pharmacol Drug Res 2002;18:6-11.

17. Teferra A, Zeruesenary D, Asfawossen GY. Prescribing pattern of drugs in medical wards of three hospitals in North-west Ethiopia. J Ethiopia Med Pract 2002;4:8-13.

18. Akande TM, Ologe MV. Prescription pattern at a secondary healthcare facility in Ilorin, Nigeria. Annals Afr Med 2007; 6:186-189 PubMed .
19. Chedi BAZ, Abdul-Aguye I, Kwanashie HO. World Health Organization core prescribing indicators; Field experience in public health facilities in Kano, Nigeria. BEST Journal 2004;6(3): 66 PubMed -70.

20. Enwere OO, Falade CO, Salako BL. Drug prescribing pattern at the medical outpatient clinic of a tertiary hospital in southwestern Nigeria. Pharmacoepidemiol Drug Saf 1997;6:319-324.

21. Babalola CP, Awoleye SA, Akinyemi JO, and Kotila OA. Evaluation of prescription pattern in Osun state (Southwest)Nigeria. Journal of Public Health and Epidemiology 2011;3(3):94-98.

22. Federal Republic of Nigeria (FRNG) Official Gazette. "Legal notice on publication of details of the breakdown of the National and State Provisional Total 2006 Census, 2007.

23. Nigeria 2006 Census Figure (Population). Retrieved May 10, 2014 from http//www.nigeriamasterweb.com/ Nigeria06CensusFigs.html

24. The creative Research Systems. The complete survey software solution since 1982. Research Aids. Retrieved April 10, 2013 from http://www.surveysystem. $\mathrm{com} / \mathrm{sscal} . \mathrm{html}$.

25. Gender in Nigeria Report 2012: Improving the Lives of Girls and Women inNigeria. Issues, Policies Action. British Council for Nigeria and UKaid-Department for International Development, 2012. Retrieved May, 10, 2014 from http://www.empowerwomen.org/. gender-in-nigeria-report-2012-improving-t.

26. World Health Organization (WHO). Gender, Women and Primary Health Care Renewal: a discussion paper. WHO Department of Gender, Women and Health (GMH), WHO 2010. Retrieved May 10, 2014 from http://www.who.int/gender/documents/women.../ en/

27. Cecile MT, vanWijk G, Husman H, Kolk AM. Gender differences in physical symptoms and illness behaviour: a health diary study. Social Science and Medicine 1999;19:1061-1074.

28. Govender V, Penn-Kekana L. Challenging gender in patient-provider interactions. In: Sen G, Ostin P, eds. Gender equality in health: the shifting frontiers of evidence and action. New York, NY and London, Routeledge, 2010.

29. Strengthening of global partnership for development in a time of crisis: MDG Task Force Report 2009. New York, NY, United Nations.

30. Nowhere to Turn: How the Individual Health Insurance Market Fails Women. Washington DC, National 
Women's Law Centre (NWLC) Report, 2008. Retrieved May 10, 2014 from http://www.action.nwlc.org/.../ PageServer?...nowheret...

31. World Health Organization (WHO). Women's health: a strategy for the African region. WHO 2005: Region for Africa, WHO. Retrieved May 10, 2014 from http:/ /www.afro.who.int/index.php?option...

32. Miller MA. Gender-based differences in the toxicity of pharmaceuticals. The Food and Drug Administration's Perspective. International Journal of Toxicology 2001;20:149-152.

33. World Health Organization (WHO). Continuity and change: implementing the third WHO medicines strategy 2008-2013. WHO Policy Perspectives on Medicines, 2010, WHO, Geneva. Retrieved October 20, 2013 from http://www.who.int/medicine/en/

34. World Health Organization (WHO). Equitable access to essential medicines: a framework for collective action. WHO, 2004. Geneva. Retrieved October 20, 2013 from http://www.who.int/medicine/en/

35. Adisa R, Fakeye TO, Fasanmade A. Medication adherence among ambulatory patients with type 2 diabetes in a tertiary healthcare setting in southwestern Nigeria. Pharmacy Practice 2011;9(2):72 PubMed -81

36.Miller RW, Rollinick S. In Motivational Interviewing: preparing people to change additive behaviour, 1991. New York, NY. Guilford Press.

37. Sleath B, Chewing B, Svardstad B, Roter D. Patient expression of compliant and adherence problems with medications during chronic disease medical visits. J Soc Admin Pharm 2000;17:71-80 PubMed .

38. R Adisa, TO Fakeye and VO Aindero. Drug prescription patterns and knowledge of dispensing process among health workers in primary healthcare facilities in Ibadan, southwestern Nigeria. International Journal of Pharmacy Practice 2014: 22 (Suppl 1):28-53

39. Eze UIH, Odunayo OO. Evaluation of drug use among diabeteic hypertensive patients in a teaching hospital. Int J Drug Dev \& Res 2010;2(4):703-710.

40. Tamuno I, Fadare JO. Drug prescription pattern in a Nigeria Tertiary Hospital. Tropical Journal Pharmacentical Research 2012;11(1):146-152.

41. Joda AE, Aderemi-Williams RJ. A comparative study of prescribing patterns in two tertiary care teaching hospitals in Lagos, Nigeria. Int, J. Pharm Pharmacol 2013; 2(1):041-046.

42. Hogerzeil HV, Bimo, Ross-Degnan D, Laing RO, Ofori-Adjei D, Santoso B, Chowdhum AKA, Das AM, Kate KK, Mabadeje AFB, Masselle AY. Field tests for rational drug use in twelve developing countries. Lancet 1993;342:1401-1410 PubMed .

43. Kafle KK, Karkee SB, Prasad RR. INRUD Drug use indicators in Nepal: Practice patterns in health post in four districts. INRUD News 1992;3:15.

44. Guvon AB, Barman A, Ahmed JU, Ahmed UA, Alam MS. Baseline survey on use of drugs at the primary healthcare level in Bangladesh Bull World Health Organization 1994;72(2):265-271.

45. Bosu WK, Ofori-Adjei D. An audit of prescribing practices in healthcare facilities of the Wassa west district of Ghana. West Afr. J. Med 2000;19(4):298 PubMed -303 .

46. Chareonkul C, Khun VI, Boonshuyar C. Rational drug use in Cambodia: study of three pilot health centres in Kampong Thorn Province. South-East Asian J Trop Med Public Health 2002; 33:418-424.

47. Lazarou J, Pomerance BH, Convey PN. Incidence of Adverse Drug Reactions in hospitalized patients: A meta-analysis of prospective studies. JAMA 1998;279(15):1200 PubMed -1205.

48. Melinda P, Talgat N, Grace H, Farruh Y, Richard L. Prescribing practices of primary healthcare physicians in Uzbekistan. J Tropical Med Int. Health 2003;8(2):182 PubMed -190 .

49. Hazra A, Tripathi SK, Alain MS. Prescribing dispensing activities at the health facilities of a non-government organization. National Med J India 2000;13(14);177-182. 50. Otoom S, Batieha A, Hadidi H, Hasan M, Al-saudi K. Evaluation of drug-use in Jordan, using WHO prescribing indicators. East Mediter. Health J 2002;8(4-5 PubMed ):537-543.

51. World Health Organization (WHO). The use of essential drugs. Seventh report of WHO Expert Committee including the revised model list of essential drugs, WHO, 1997. Geneva. Retrieved April 20, 2014 from http://www.who.int/medicine/

52. Federal Republic of Nigeria. National antimalarial treatment guidelines. Federal Republic of Nigeria Roll back malaria training manual on malaria control for primary health care workers in Nigeria. Federal Ministry of Health National Malaria and Vector Control division, Abuja, Nigeria, March 2005.

53. Olayemi SO, Akinyede AA, Oreagba AJ. Prescription pattern at primary health care centres in Lagos state. Nig Postgrad Med J 2006;13:220-224 PubMed .

54. Odusanya OO, Oyediran MA. Rational drug use at the primary healthcare centres in Lagos, Nigeria. Nigerian Quart J Hosp Med 2000;10:4-7. 